Kirkpatrick, B., Fenton, W. S., Carpenter, W. T., et al (2006) The NIMH MATRICS consensus statement on negative symptoms. Schizophrenia Bulletin, 32, 214-219.

Lehman, A. F., Kreyenbuhl, J., Buchanan, R. W., et al (2004) The Schizophrenia Patient Outcomes Research Team (PORT). Schizophrenia Bulletin, 30, 193-217.

Malla, A. K., Norman, R., Manchanda, R., et al (2002) One year outcome in first episode psychosis: influence of DUP and other predictors. Schizophrenia Research, 54, 231.

Malla, A. K., Bodnar, M., Joober, R., et al (2011) Duration of untreated psychosis is associated with orbital-frontal grey matter volume reductions in first episode psychosis. Schizophrenia Research, $125,13-20$

Milev, P., Ho, B. C., Arndt, S., et al (2005) Predictive values of neurocognition and negative symptoms on functional outcome in schizophrenia: a longitudinal first-episode study with 7-year followup. American Journal of Psychiatry, 162, 495-506.

Möller, H. J. (2003) Management of the negative symptoms of schizophrenia. CNS Drugs, 17, 793-823.

Möller, H. J. (2007) Clinical evaluation of negative symptoms in schizophrenia. European Psychiatry, 22, 380-386.

Perlick, D., Rosenheck, R., Kaczynski, R., et al (2006) Special section on CATIE baseline data: components and correlates of family burden in schizophrenia. Psychiatric Services, 57, 1117-1125.

Rector, N. A. \& Beck, A. T. (2001) Cognitive behavioral therapy for schizophrenia: an empirical review. Journal of Nervous and Menta Disease, 189, 278-287.

Wykes, T., Steel, C. \& Everitt, B. (2008) Cognitive behavior therapy for schizophrenia: effect sizes, clinical models, and methodological rigor. Schizophrenia Bulletin, 34, 523-537.

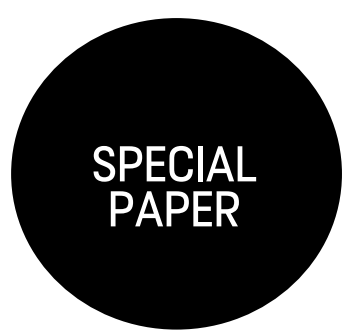

\title{
Psychosocial research with children in Iraq: current health practice and policy in a context of armed conflict
}

\author{
Abdul Kareem Al Obaidi, ${ }^{1}$ Tim Corcoran ${ }^{2}$ and Leslie Scarth ${ }^{3}$
}

'Visiting Scholar, Institute of International Education, New York, USA, email kareemo gmail.com

${ }^{2}$ Victoria Institute, Victoria University, Melbourne, Australia

${ }^{3}$ Consultant Child and Adolescent Psychiatrist, Edinburgh, UK
There is a need to show how psychosocial issues affect children in conflict areas like Iraq. Raising knowledge and awareness of children's mental health status in Iraq has been difficult and the knowledge base has been limited by the shortage of resources, international sanctions and the isolation of Iraqi scholars. Many obstacles to research in Iraq exist but an agenda should be developed emphasising the need for high-quality contextualised psychosocial research. Health researchers in the country need to clarify basic population parameters and to provide culturally appropriate, evidence-based interventions for practitioners.

Much attention has been paid to researching children affected by war and violent conflicts. Major areas of study explore the impact of war on children's health, including the relationship between experiences of conflict and mental health. People in conflict situations experience many psychosocial problems (e.g. personal isolation, interpersonal stress). However, communities rarely have capacity (e.g. mental health resources) to counteract such adverse circumstances. Research can aid in the evaluation of intervention programmes and influence both policy development and future practice, but logistics, methodological and ethical issues, as well as difficulties in measuring intervention effectiveness, present ongoing challenges for researchers in conflict zones. These issues are particularly concerning when researching children (Sondheimer \& Rey, 2012).

Recent social and political instability in Iraq presents a particular dilemma for scholars and investigators. War, economic sanctions and the departure of health professionals during the dictatorship destroyed the country's social service infrastructure. Moreover, after the 2003 war, direct death threats made against those with higher education, perceived as either powerful or wealthy, or both, has reduced the availability of teachers in tertiary education in particular, contributing to the collapse of research activity. This has led to the loss of the scientific research base for social studies in the community, particularly the evidence base for children's health and education services. The psychosocial status of Iraqi children and adolescents is substantially affected by the current environment, which undermines best practice and evidence-based interventions. The need remains to show how psychosocial issues affect health practices and policies involving children in conflict areas like Iraq.

\section{Children's psychosocial issues as a research arena in Iraq}

Various factors contribute to child development and psychosocial well-being (e.g. socioeconomic status, educational attainment). Investigation of these issues is a challenge in both peaceful and conflict areas. Globally, child and adolescent mental health problems present high demands on care services in the face of diminishing resources (Belfer, 2008).

Raising knowledge and awareness of children's mental health status in Iraq has been difficult due to unsystematic coverage of the topic in the literature. While there is some interest in scientific exploration, its scope is limited. For example, it is difficult to source publications targeting childhood mental health prior to 2003. Factors like the 
shortage of resources, international sanctions and the isolation of Iraqi scholars from the rest of the world have limited scientific studies in general, including research involving children's welfare issues. However, there are exceptions worth noting.

During 1991, a study was conducted by members of an international team from the Centre for Crisis Psychology in Norway. This team assessed the impact of the 1991 Gulf War on Iraqi children using the Impact of Event Scale (IES) with 94 Iraqi children (Dyregrov et al, 2002). Using this work, the United Nations Children's Fund (UNICEF) presented guidelines for child protection policy and programmes to assist Iraqi children who suffered in the war (UNICEF, 2003).

In 1998, a study on the prevalence of symptoms of post-traumatic stress investigated a sample of displaced children living on the Iraqi-Turkish border in Kurdistan (northern Iraq) in the aftermath of the 1991 Gulf War. It found that $20 \%$ of the sample was affected by post-traumatic stress disorder (PTSD) (Ahmad et al, 1998).

In 1999, a study in Baghdad estimated the prevalence of attention-deficit hyperactivity disorder (ADHD) among primary schoolchildren at $11 \%$ (Al-Obaidi \& Ali, 2009).

Since 2003, a number of studies and articles conducted by Iraqi and non-Iraqi researchers have been published in international peer-reviewed journals. Only $2 \%$ of all health research in Iraq conducted between 2000 and 2005 tackled mental health issues (World Health Organization \& Iraqi Ministry of Health, 2006). One of the main themes was the post-war impact of violence on the mental and psychological well-being of Iraqi children. Some studies have estimated the prevalence of mental disorders among samples of Iraqi children. In Mosul (a large city in the north of Iraq), mental disorders were found in $37 \%$ of children attending primary healthcare (Al-Jawadi \& Abdul-Rahman, 2007). Among a clinical sample of children in Baghdad, 22\% had diagnoses of anxiety disorders and $18 \%$ behavioural disorders (Al-Obaidi et al, 2010a).

A small number of research efforts have led to proposals for the development of child protection programmes and the building and promotion of a child-centred mental health system in Iraq. Also required is the development of curricula for training front-line paediatricians in children's psychosocial issues, and supporting inclusive education for children with physical and mental disabilities (AlObaidi et al, 2009, 2010b, 2012, 2013; Al-Obaidi \& Budosan, 2011).

The main obstacles confronting researchers in Iraq include: shortage of human resources to conduct studies; lack of funding; lack of appropriate research tools and research training of local professionals; low priority of data collection by state agencies; poor awareness of child mental health issues; and threats related to the safety of research teams in insecure areas. In spite of the abovementioned studies, the paucity of published data makes it difficult to obtain precise numbers on the prevalence and severity of childhood psychological problems in a country where child mental health services are almost non-existent (Al-Obaidi et al, 2010b). This complicates the framing of evidencebased treatments, programme planning and the establishment of policy benefiting Iraqi children.

\section{Child psychosocial research: health practice and policy}

Research outcomes contribute to helping practitioners develop effective interventions (Hart \& Tyrer, 2006). Research on childhood psychosocial issues in the context of war and conflict has a direct and an indirect impact on policy and practice (Boyden, 2003). Children need stable, continuous and predictable programmes, focusing on treatment, rehabilitation, family and social reintegration. Children's responses to adversities or catastrophes are universal, and family support in times of crises is of proven benefit (Boyden, 2003). Such attention has led to a shift in intervention programme priorities, from the supply of physical aid, to integrating mental health provisions within intervention programmes (e.g. in Kosovo, Bosnia, Rwanda, Afghanistan and Iraq).

Many obstacles to research in Iraq exist but an agenda should be developed emphasising the need for high-quality contextualised psychosocial research. Health researchers in the country need to clarify basic population parameters and to provide culturally appropriate, evidence-based interventions. Locally based research should avoid possible mistakes from poorly conceived intervention programmes. Iraq presents a good climate for research and a regrowth of the country's academic community is being seen. The assistance of outside agencies in collaboration with Iraqi colleagues can be a joint learning exercise benefiting both parties and the population in the development of contextspecific practices.

\section{References}

Ahmad, A., Mohamed, H. T. \& Ameen, N. M. (1998) A 26-month follow-up of posttraumatic stress symptoms in children after the mass escape tragedy in Iraqi Kurdistan. Nordic Journal of Psychiatry, 52, 357-366.

Al-Jawadi, A. A. \& Abdul-Rhaman, S. (2007) Prevalence of childhood and early adolescence mental disorders among children attending primary health care centers in Mosul, Iraq: a cross sectional study. BMC Public Health, 7, 274.

Al-Obaidi, A. K. \& Ali, N. S. (2009) Attention deficit/hyperactivity disorder among schoolchildren in Baghdad. Journal of the Canadian Academy for Child and Adolescent Psychiatry, 18, 4-5.

Al-Obaidi, A. K. \& Budosan, B. (2011) Mainstreaming educational opportunities for physically and mentally disabled children and adolescents in Iraq. Advances in School Mental Health Promotion, 4, 35-43.

Al-Obaidi, A. K., Jeffrey, L. R., Scarth, L., et al (2009) Iraqi children rights: build a system under fire. Medicine, Conflict and Survival, 25 , 145-162.

Al-Obaidi, A. K., Scarth, L. \& Dwivedi, K. N. (2010a) Mental disorder in children attending child psychiatric clinic at the general paediatric hospital in Baghdad. International Journal of Mental Health Promotion, 12, 24-30.

Al-Obaidi, A. K., Budosan, B. \& Jeffery, L. (2010b) Child and adolescent mental health in Iraq: current situation and scope for promotion of child and adolescent mental health policy. Intervention, 8, 40-51. 
Al-Obaidi, A. K., Nelson, B. D., AlBadawi, G., et al (2012) Child mental health and service needs in Iraq: beliefs and attitudes of primary school teachers. Child and Adolescent Mental Health (doi:10.1111/j.1475-3588.2012.00670.x).

Al-Obaidi, A. K., Corcoran, T., Hussein, M. A., et al (2013) Psychosocial paediatric training in Iraq: perspectives of trainers and students. Medicine, Conflict and Survival, 29, 45-56.

Belfer, M. L. (2008) Child and adolescent mental disorders: the magnitude of the problem across the globe. Journal of Child Psychology and Psychiatry, 49, 226-236.

Boyden, J. (2003) Children under fire: challenging assumptions about children's resilience. Children, Youth and Environments, 13(1).
Dyregrov, A., Gjestad, R. \& Raundalen, M. (2002) Children exposed to warfare: a longitudinal study. Journal of Traumatic Stress, 15, 59-68.

Hart, J. \& Tyrer, B. (2006) Research With Children Living in Situations of Armed Conflict: Concepts, Ethics, \& Methods. University of Oxford, Refugee Study Centre.

Sondheimer, A. \& Rey, J. M. (2012) Ethics and international child and adolescent psychiatry. In IACAPAP e-Textbook of Child and Adolescent Mental Health (ed. J. M. Rey). pp. 20-22. International Association for Child and Adolescent Psychiatry and Allied Professions.

UNICEF (2003) Iraq Watching Brief. Children Protection. UNICEF.

World Health Organization \& Iraqi Ministry of Health (2006) WHOAIMS Report on Mental Health System in Iraq. Iraqi Ministry of Health.

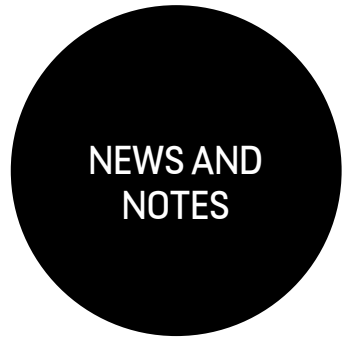

Contributions to the 'News and notes' column should be sent to ip@rcpsych.ac.uk

\section{Faculty of the Psychiatry of Old Age: bursary for psychiatrists from developing countries}

The Faculty of the Psychiatry of Old Age has established an annual bursary to enable a psychiatrist from a developing country to attend the Faculty Annual Residential Meeting (usually held in March) in order to give an oral or poster presentation, or deliver a workshop. The bursary is intended to cover the cost of economy-class travel, accommodation, free registration and attendance at the conference dinner, up to a maximum of $£ 1500$. Informal mentors will be identified for the bursary holder to enhance their introduction to Faculty members and their enjoyment of the meeting. See http://www.rcpsych.ac.uk/workinpsychiatry/faculties/oldage/aboutthefaculty/prizesandbursaries. aspx\#develop.

The closing date is 31 October.

\section{The Dublin Declaration}

On Friday 24 May, over 193 delegates from 21 European countries met in Dublin to discuss the needs of family carers for people with mental ill health. Addressing the conference, Dr Tonio Borg, European Commissioner for Health and Consumer Affairs, stressed the importance of family involvement in mental healthcare across Europe.

The Irish Minister of State, Kathleen Lynch $\mathrm{TD}$, declared at the conference that good mental health was a partnership between government, professionals, people with experience of mental ill health and family members.

Throughout the day, the audience heard presentations on the importance of family involvement, the need for education, quality information and communication in helping families to cope with mental ill health.

Against this background, the delegates unanimously agreed the Dublin Declaration 2013, which is available from the website of the European Federation of Associations of Families of People with Mental Illness (http://www.eufami.org).

Rita Geerts, Administrator, European Federation of Associations of Families of People with Mental Illness
The mental health component of undergraduate medical training in Somaliland

Somaliland is a self-declared independent state, although recognised by the World Health Organization (WHO) and internationally as Northern Somalia. It is a region which has experienced conflict and severe poverty, although it has remained relatively stable in recent years despite the challenges it continues to face. Many healthcare professionals were forced to leave the region or were killed during the civil war, which began in 1991. This has led to a need to strengthen and build upon existing healthcare services.

There are currently no practising psychiatrists in Somaliland and there exists a stark shortage of good mental healthcare. The King's-THET Somaliland Partnership (KTSP) has been providing the mental health component of undergraduate medical training since 2008. Without this, there would be no mental health input for medical professionals.

May 2013 saw the annual training trip to Hargeisa, the capital of Somaliland. Both of the present authors (a CT3 in psychiatry and a consultant psychiatrist) led the training this year, in conjunction with Somaliland colleagues on the ground. The trip started in Nairobi, where a small plane was boarded to Hargeisa. An unexpected surprise entailed passing right over the runway in Hargeisa and landing in the bush as the runway was closed temporarily.

The next 2 weeks were spent carrying out intensive mental health training for medical students in their penultimate year of study. This was based on the WHO Mental Health Gap (mhGAP) Action Programme. The KTSP group has piloted the incorporation of the mhGAP Intervention Guide, an evidence-based guide for mental, neurological and substance misuse disorders, into the medical undergraduate curriculum for the first time worldwide in Northern Somalia. The aim is to ensure non-specialists, as many of the medical students will turn out to be, may deliver good mental healthcare as they become clinicians following graduation. This is important in a region 